\title{
The use of community treatment orders in competent patients is not justified
}

Giles Newton-Howes and Christopher James Ryan

\section{Summary}

Empirical evidence for the effectiveness of community treatment orders (CTOS) is at best mixed. We examine CTOs through the prism of human rights and discrimination, bearing the evidence in mind, and argue that a necessary condition for their use is that a person lacks decision-making capacity.

Giles Newton-Howes (pictured) is a senior lecturer at the University of Otago in Wellington and consultant psychiatrist and clinical leader, community in Te-Upoko-me-te-Whatu-o-Te-kka Mental Health, Addictions and Intellectual Disability Service, New Zealand. Chris Ryan is a clinical associate professor and consultation-liaison psychiatrist at Sydney's Westmead Hospital.

Whether or not community treatment orders (CTOs) benefit patients is far from clear. Studies of differing quality and design have examined different outcomes and yielded conflicting results. The issue is further complicated by jurisdictional differences that make it impossible to compare these studies directly. Not only does the legislation supporting CTOs differ significantly from jurisdiction to jurisdiction, but areas apply differing models of psychiatric care to patients of often vastly different demographics. All in all, it seems unlikely that any one study will provide the definitive answer to the question: do CTOs work? Nonetheless, despite the poverty of evidence of effectiveness, the use of CTOs continues to increase internationally. ${ }^{1}$ Here we reconsider CTOs through an ethical and legal lens and argue that their use should be dramatically reduced. Moreover, we argue that they should not be used at all in patients who retain decision-making capacity. A position based not only on the lack of evidence of effectiveness but on the discrimination and significant human rights breaches inherent in their use in this population.

\section{CTOs, human rights and discrimination}

Although few would suggest that, at least, some forms of involuntary in-patient psychiatric treatment cannot be ethically justified, moral arguments for the forced treatment of people well enough to be living in the community are harder to build and maintain. This is primarily because some CTO legislation, like that governing CTO use in England and Wales and in some US and Australasian juristictions (e.g. Mental Health (Compulsory Assessment and Treatment) Act 1992 (NZ)), facilitates compulsory community treatment even if a patient competently refuses it - we will refer to CTOs of this form as 'traditional' CTOs. Many people who are well enough to be living in the community will also be well enough to competently refuse the treatment recommended for their mental illness. The clash of forced treatment against competent refusal created by these traditional CTOs provides a basis for strong ethical arguments against them based on the grounds of both discrimination and human rights violations. ${ }^{2,3}$

Human rights arguments against CTOs have come to increasing prominence in recent years since the advent of the

\section{Declaration of interest}

C.J.R. gives occasional medicolegal opinions in which the appropriate application of community treatment orders are at issue.

\section{Copyright and usage}

(c) The Royal college of Psychiatrists 2017.
United Nations Convention on the Rights of Persons with Disabilities (CRPD) that most nations have now either signed or ratified. The CRPD was constructed around the social model of disability, and places much of the burden of 'disability' in the context of the community's failure to make appropriate accommodation for impairment. States parties, which have ratified the CRPD, have committed to reforming mental health law so that it does not discriminate on the basis of disability, and the CRPD defines 'disability' to include, at least, chronic mental illness. Since, in almost all circumstances, competent individuals have a right to refuse medical treatment and since traditional CTOs facilitate treatment even when a person with a mental illness competently refuses it, traditional CTOs violate that right of refusal on the basis of the presence of disability alone.

Many psychiatrists have become so familiar with this aspect of traditional CTOs that some may not see immediately how ethically troublesome the forced treatment of a competent individual might be. A comparison with a parallel situation in general medicine may make this clearer. Most jurisdictions have legislative provisions that would allow people with influenza to be forced to take treatment in spite of a competent refusal in the event of an outbreak of a particularly virulent strain. However, even though the magnitude of the risks to self or others is often far greater in the case of influenza than it is mental illness, these legislative provisions are almost never used, even in the face of serious outbreaks, so great is our respect for the autonomy of competent individuals. ${ }^{4}$

\section{Other arguments advanced to justify CTOs}

Many psychiatrists seem to have adopted a position whereby, no matter what the rights-based arguments, they are supportive of CTOs perhaps seeing them as an extension of the justified coercion in in-patient services. However, increasingly, even this approach is coming under pressure.

Since the initiation of CTOs there has been little evidence of any benefit to those subjected to them. There have been three controlled trials of CTOs, all of them traditional CTOs in the sense we are using that term, conducted across a range of jurisdictions, including one conducted in the UK. ${ }^{5}$ Although all three have been subject to criticism, all have been essentially negative with respect to benefit. Notably, meta-analysis of the three studies does not suggest CTOs reduce readmission or bed days. ${ }^{6}$

Additionally, even if CTOs do provide those subject to them with some benefit, it may be that that benefit derives not from 
their coercive effect per se, but via an administrative mechanism that simply signals to community health services that these patients should have priority access to their care. As a result of that administrative signal, patients on CTOs may get more services and any beneficial effect of a CTO may be simply down to that. The notion that patient rights are being routinely abrogated to allow services to better organise their resources is nothing short of Kafkaesque. The fact that this form of triage results in no, or only marginal, benefit is to add insult to injury both for the individual and to a system that tacitly accepts the delivery of a two-tiered system of care. Moreover, this ranking by legal status perversely encourages patients and their families to accept a CTO in order to access greater service provision.

The options presented to patients frequently presume only two choices - hospital or a CTO - while ignoring the obvious third choice, voluntary community treatment without a CTO. This false dichotomy levers patients and their families to access a CTO where they may prefer not to, fearing the loss of service provision. Recognition of the rights of patients to make informed choices not only reflects a literature that suggests that a high proportion of patients with mental illness retain decision-making capacity, but it is consistent with a recovery focus, as recovery becomes a guiding principle for mental health services.

\section{CTOs for those who lack decision-making capacity}

What then is the future for CTOs? It is time to admit that our well-intentioned efforts have revealed themselves to be fruitless and that the traditional conception of CTOs has passed its use-by date. We need to accept that the argument that was often used to introduce CTOs, that of reducing asylum-based hospital care, can no longer be supported. Law-makers need to recognise the influence of their obligations under international law and work to radically amend the legislation that supports CTOs. It is time for medical professionals to accept that the weight of evidence does not support the utility of CTOs and we are, therefore, ethically obliged to stop utilising them as we currently do. The place of CTOs in psychiatric care needs to be reconceptualised.

It is possible that there is a cohort of patients, much smaller than the number made subject to traditional CTOs currently, who, although well enough to live safely in the community, nonetheless lack decision-making capacity around the issue of receipt of psychiatric treatment. ${ }^{7}$ These are people who have largely recovered, but who still, despite our best efforts at support and education, either do not understand the information relevant to the treatment offered or cannot use and weigh that information as a result of the effects of their mental illness. The state has long recognised a responsibility to protect those who cannot, by reason of mental incapacity, protect themselves, so to the extent that CTOs may show efficacy this perhaps should be the population targeted. The ethical problems with CTOs highlighted above are largely mitigated in this group. ${ }^{8}$ Moreover, it is possible that it is these very people who might particularly benefit from a CTO. Perhaps the reason that the benefits of CTOs are often not identified in the trials currently conducted, is that the orders are being used indiscriminately and a possible strong benefit when directed to patients who lack capacity is being washed out by their use in many people with mental illness capable of deciding for themselves. At the very least this is a hypothesis worth further investigation, ideally by randomised controlled trials, or alternatively by cohort studies, designed as much as possible to control for the possibility that CTOs may provide an administrative signal for priority access to care.

At this point whether CTOs might assist even people who have lost decision-making capacity remains speculative, but here, at least, arguments based on rights and discrimination are much less potent. Most Australian jurisdictions have very recently reformed their mental health acts to either prohibit or strongly discourage forced psychiatric treatment in those who retain capacity. ${ }^{9}$ Many other jurisdictions have always limited the use of CTOs to those patients who lack decision-making capacity. This trend to see incapacity as a necessary criterion in provisions allowing CTOs is being examined internationally and provides the opportunity for pragmatic, whole of population research to be undertaken.

In the meantime, the use of these orders to force community treatment upon individuals who competently refuse treatment can no longer be justified and should immediately stop.

Giles Newton-Howes, MBChB, MRCPsych, FRANZCP, Department of Psychological Medicine, University of Otago, Wellington, New Zealand; Christopher James Ryan MBBS, MHL, FRANZCP, Discipline of Psychiatry and the Centre for Values, Ethics and the Law in Medicine, University of Sydney, Sydney, Australia

Correspondence: Giles Newton-Howes, Department of Psychological Medicine, Otago University, PO Box 7343, Wellington, New Zealand 6242. Email: giles.newton-howes@otago.ac.nz

\section{References}

1 Gordon SE, O'Brien A. New Zealand's mental health legislation needs reform to avoid discrimination. NZ Med J 2014; 127: 55-65.

2 Dale E. Is supervised community treatment ethically justifiable? I Med Ethics 2010; 36: 271-4.

3 Dawson J. Community treatment orders and human rights. Law Context 2008; 26: 148-59.

4 Ryan CJ. One flu over the cuckoo's nest: comparing legislated coercive treatment for mental illness and other illness. J Bioeth Inq 2011; 8: 87-93.

5 Burns T, Rugkåsa J, Molodynski A, Dawson J, Yeeles K, Vazquez-Montes M, et al. Community treatment orders for patients with psychosis (OCTET): a randomised controlled trial. Lancet 2013; 381: 1627-33.

6 Kisely S, Hall K. An updated meta-analysis of randomized controlled evidence for the effectiveness of community treatment orders. Can J Psychiatry 2014; 59: $561-4$.

7 Milne D, O'Brien A, McKenna B. Community treatment orders and competence to consent. Australas Psychiatry 2009; 17: 273-8.

8 Szmukler G. Is there a place for community treatment orders after the OCTET study? Acta Psychiatr Scand 2015; 131: 330-2.

9 Callaghan S, Ryan CJ. An evolving revolution: evaluating Australia's compliance with the Convention on the Rights of Persons with Disabilities in mental health law. Univ NSW Law J 2016; 39: 596-624. 